\title{
Article
}

\section{Strategi Politik Partai Perindo Dalam Mendulang Suara Pada Pemilihan Legislatif Tahun 2019}

\author{
Nazaruddin ${ }^{1 *}$, Warsono ${ }^{2}$
}

This article is an open access article distributed under the terms and conditions of the Creative Commons Attribution-ShareAlike 4.0 International (CC BY SA ) License (https://creativecommo ns.org/licenses/by$\mathrm{sa} / 4.0 /)$.

\section{Jurnal Politik dan} Pemerintahan Daerah ISSN 2686-2271

Fakultas Ilmu Sosial dan Ilmu Politik, Universitas Muara Bungo Jl. Diponegoro No. 27, Muara Bungo-Jambi, (0747) 323310

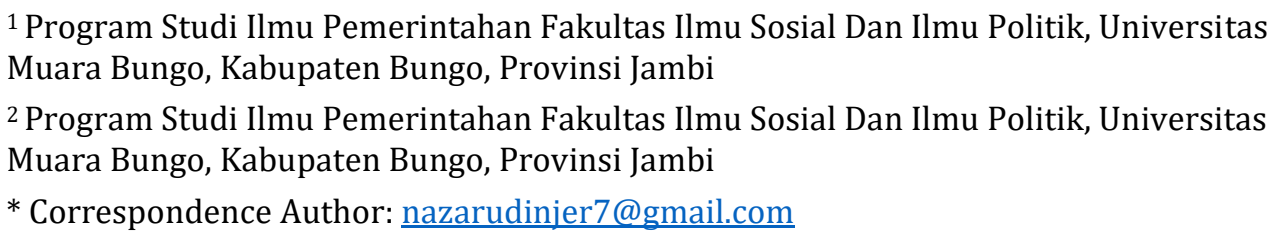

Abstract: The purpose of this study was to find out the political strategy of the Perindo Party DPD in Merangin Regency in gaining votes in the 2019 legislative election and to find out the obstacles the Perindo Party DPD in Merangin Regency had to implement the political strategy of the Merangin Regency Perindo Party DPD to gain votes in parliament in the 2019 legislative election. The method used in this study is a qualitative research method with a descriptive study. The method used in this study is a qualitative research method with a descriptive study. The informant selection technique used by the researcher in this study was to use the purposive sampling method (sampling technique with certain considerations). The results of this study indicate that the political strategy of the DPD Perindo Party in Merangin Regency in gaining votes in parliament in the 2019 legislative election includes socializing programs and party imagery as well as mapping potential electoral districts by placing community leaders as candidates. Obstacles to the Perindo Party DPD in Merangin Regency in implementing a political strategy to win the 2019 General Election include the low level of public political participation and the existence of money politics by other party candidates. It is hoped that the Perindo Party will provide political education to the public through its cadres who are registered in legislative candidates based on their respective electoral districts through healthy political education, so that the Perindo party will not only win the 2019 election but also win the hearts of the people.

Keywords: Political Strategy, Gaining Votes, 2019 Legislative Election

Abstrak: Tujuan dilakukan penelitian ini adalah untuk mengetahui strategi politik DPD Partai Perindo Kabupaten Merangin dalam mendulang suara pada pemilihan legislatif tahun 2019 dan untuk mengetahui kendala DPD Partai Perindo Kabupaten Merangin menerapkan strategi politik DPD Partai Perindo Kabupaten Merangin untuk mendulang suara di parlemen pada pemilihan legislatif tahun 2019. Metode yang digunakan dalam penelitian ini penelitian ini adalah metode penelitian kualitatif yang bersifat dengan studi deskriptif. Metode yang digunakan dalam penelitian ini penelitian ini adalah metode penelitian kualitatif yang bersifat dengan studi deskriptif. Teknik pemilihan informan yang digunakan oleh peneliti dalam penelitian ini adalah dengan menggunakan metode purposive sampling (teknik penentuan sampel dengan pertimbangan tertentu). Hasil penelitian ini menunjukkan bahwa Strategi politik DPD Partai Perindo Kabupaten Merangin dalam mendulang suara di parlemen pada pemilihan legislatif tahun 2019 diantaranya adalah melakukan sosialisasi program dan pencitraan partai serta melakukan pemetaan dapil potensial dengan menempatkan tokoh masyarakat sebagai caleg. Kendala DPD Partai Perindo Kabupaten Merangin 
dalam menerapkan strategi politik untuk memenangkan Pemilu 2019 diantaranya adalah rendahnya partisipasi politik masyarakat dan adanya politik uang yang dilakukan caleg partai lain. Diharapkan Partai Perindo memberikan pendidikan politik kepada masyarakat melalui kadernya yang terdaftar di caleg berdasarkan dapil masing-masing melalui edukasi politik sehat, agar partai Perindo tidak hanya memenangkan Pemilu 2019 namun juga memenangkan hati masyarakat

Kata Kunci: Strategi politik, Mendulang Suara, Pileg 2019

\section{Pendahuluan}

Partai politik berangkat dari anggapan bahwa dengan membentuk wadah organisasi mereka bisa menyatukan orang- orang yang mempunyai pikiran serupa sehingga pikiran dan orientasi mereka bisa dikonsolidasikan. Dengan begitu pengaruh mereka bisa lebih besar dalam pembuatan dan pelaksanaan keputusan. Partai politik didirikan untuk mendapatkan dan mempertahankan kekuasaan, baik di level lokal maupun nasional. (Budiardjo, 2009). Secara umum dapat dikatakan bahwa partai politik adalah suatu kelompok terorganisir yang anggota- anggotanya mempunyai orientasi, nilai- nilai dan cita-cita yang sama. Dengan adanya partai politik, masyarakat dapat merasakan negara/pemerintahan yang nyata dikarenakan partai politik berperan sebagai pihak penyeimbang dari penguasa yang berperan dalam pemerintahan dengan memperoleh dukungan rakyat (Prasetya, 2011). Tujuan kelompok ini ialah untuk memperoleh kekuasaan politik dan merebut kedudukan politik biasanya dengan cara konstitusional untuk melaksanakan programnya. (Budiardjo, 2009). Sepanjang sejarah, pemilihan umum di Indonesia selalu menganut sistem multi parpol. Sepanjang sejarah itu pula partai politik lahir dan kandas. Beberapa bertahan dan terus menguat, sementara kebanyakan tidak mampu merebut suara yang cukup untuk melanjutkan agenda perjuangannya. UU Nomor 2 Tahun 2011 Tentang Perubahan Atas UU No. 2 Tahun 2008 Tentang Partai Politik memberikan syarat yang cukup berat untuk dapat membentuk sebuah partai politik. Seberat apapun, peluang untuk membentuk partai politik baru tetap terbuka.

Partai politik, jika tidak disebut sebagai satu-satunya, merupakan saluran politik yang legal dalam upaya-upaya untuk merebut kekuasaan. Kehadiran partai baru dari masa ke masa merupakan salah satu indikator rendahnya kepercayaan (sebagian) publik pada partai politik yang sudah ada. Namun apakah partai politik baru ini dapat menjawab harapan dari publik?

Untuk menilai sebuah partai politik kita harus berangkat dari alat ukur yang tepat. Pertama tentunya harus menilai ideologinya, namun asas tunggal Pancasila tidak membuka peluang bagi siapapun untuk keluar dari ideologi tersebut. Selanjutnya yang kedua adalah platform politik, sebuah partai politik dapat dibedakan dari partai politik lain melalui platformnya yang ditunjukan melalui visi dan misi. Pada dasarnya, semua partai juga menawarkan kesejahteraan, kehidupan yang lebih baik, dan keadilan bagi seluruh rakyat Indonesia. Partai politik digunakan untuk menciptakan masyarakat yang dicita-citakan dalam pemerintahan yang adil melalui pemilihan umum (Prasetya, 2011).

Dan yang ketiga, adalah implementasi fungsi partai politik melalui kontribusi kepada masyarakat terutama konstituennya. Melalui telaah fungsi ini kita bisa menilai apakah suatu partai politik sudah bisa menjawab harapan masyarakat atau hanya digunakan sebagai kendaraan untuk merebut kekuasaan saja. Adapun fungsi partai politik menurut Sukarna adalah sebagai berikut: (1) Edukasi politik, (2) Sosialisasi politik, (3) Seleksi politik, (4) Artikulasi kepentingan, (5) Mengelola konflik, (6) Komunikasi politik, (7) Kontrol politik atau kritik terhadap rejim, (8) 
Merangsang opini publik, (9) Mencalonkan kandidat, (10) Memilih pejabat publik, dan (11) Agregasi politik. (Sukarna, 2002). Dalam negara demokrasi masa kini, keberadaan partai politik dianggap penting sebagai salah satu atribut negara yang kehadirannya diperlukan bagi negara yang merdeka dan berdaulat (Pasaribu, 2017).

Sebagai partai politik yang baru dan belum menjadi peserta pemilu sehingga belum memiliki representasi di legislatif, tentu saja Perindo belum bisa melaksanakan semua fungsi partai politik yang diutarakan di atas. Namun harus diakui bahwa Perindo sudah melakukan edukasi politik dan sosialisasi dengan gencar, misalnya melalui publikasi platform politik (Mengenal Platform Partai Perindo), mempopulerkan Mars Perindo, dan reportase kegiatan Ketua Umumnya saat melantik pengurus tingkat desa atau kelurahan di berbagai media massa eletronik dan cetak milik MNC Group, website, media sosial (Langkah HT fanpage), dan juga mewarnai forum-forum diskusi online. Melalui upaya gencar ini juga, Hary Tanoesoedibjo sebagai Ketua Umum Perindo secara simultan berhasil melaksanakan fungsi komunikasi politik dan merangsang opini publik.

Perindo terpantau sudah mulai menyiapkan sistem untuk seleksi politik dan mencalonkan kandidat, memilih kadernya yang akan didorong untuk menduduki jabatan publik baik di pusat maupun daerah. Termasuk dengan menyatakan dukungan kepada beberapa calon kepada daerah pada pemilukada serentak 2015 lalu. Namun secara formal belum dapat dicatat sebagai keberhasilan Perindo karena saat hal tersebut dilakukan Perindo belum menjadi partai pengusung maupun pendukung. Hal ini bisa diukur sebagai upaya sungguh-sungguh Hary Tanoesoedibjo untuk mempengaruhi konstelasi politik di daerah, bukan sekedar meramaikan saja.

Oleh karena itu, bukan tanpa alasan Perindo diprediksi akan menjadi partai politik pendatang baru yang akan melesak masuk ke jajaran papan atas partai politik Indonesia di Pemilu 2019 nanti. Bahkan Saiful Mujani Research and Conculting (SMRC) memprediksi Hary Tanoesoedibjo termasuk lima besar tokoh yang berpotensi menjadi Presiden Republik Indonesia 2019 (Kurniawan, 2015).

Hasil survei Institute of Transformation Studies (Intrans) menunjukkan Partai Persatuan Indonesia (Perindo) pimpinan pengusaha Hary Tanoesoedibjo sebagai partai politik paling aktif kampanye di media sosial. Dimana Perindo menempati posisi teratas dengan jumlah aktivitas tertinggi, yakni 2.590 kali. Aktivitas hampir merata di seluruh platform (Armenia, 2016). Intrans menggelar penelitian dengan metode triangulasi untuk memperoleh gambaran tentang perilaku pemilih di media sosial, terutama dari lima platform utama, yakni Facebook, Twitter, Instagram, Google, dan YouTube. Intrans mengamati akun-akun resmi partai politik yang diinformasikan melalui iklan atau situs resmi partai tersebut. Intrans melakukan pengamatan terhadap konten berbentuk teks, video, gambar, dan lain-lain. Sebagaimana terlihat pada tabel berikut ini:

\begin{tabular}{|c|c|c|c|}
\hline No & Media & Aktivitas & Keterangan \\
\hline 1 & Twitter & $17.3 \mathrm{k}$ & Retweets Likes \\
\hline 2 & Facebook & $22.1 \mathrm{k}$ & Post Likes, Post Comments, Post Shares \\
\hline 3 & Google+ & 0 & \\
\hline 4 & Youtube & 35 & Post Likes, Post Dislikes, Post Comments \\
\hline 5 & Instagram & $6.40 \mathrm{k}$ & Post Likes, Post Comments \\
\hline
\end{tabular}

Sumber : www.instrans.co.id

Pemilu 2019 tidak lama lagi. Partai politik sudah mempersiapkan diri untuk bersaing. Tidak hanya partai politik yang sudah lama berdiri dan telah berulang kali mengikuti pemilu, namun Partai politik yang barupun melakukan hal yang sama, tidak terkecuali Partai Perindo. Berbagai macam cara dilakukan untuk meraih 
simpati masyarakat selaku pemilih, baik melalui kegiatan sosial maupun kegiatan keagamaan. Berikut merupakan program bantuan Perindo bagi masyarakat:

Tabel 2. Program Bantuan Partai Perindo

\begin{tabular}{l|ll|ll|l} 
No & \multicolumn{2}{|c|}{ Jenis Bantuan } & \multicolumn{2}{|c|}{ Sasaran } & Keterangan \\
1 & Ambulan & & & \\
2 & Masyarakat umum & & \\
Pedagang & Kaki & \\
Lima/UMKM & & \\
UMKM & $\begin{array}{l}\text { Pembinaan usaha } \\
\text { menengah }\end{array}$ & kecil dan & &
\end{tabular}

Upaya yang dilakukan tersebut di atas serta mengiklankan partai melalui berbagai media tidak lain merupakan strategi politik partai demi memenangkan pemilu 2019. Berdasarkan uraian diatas maka penulis tertarik untuk meneliti lebih lanjut mengenai "STRATEGI POLITIK PARTAI PERINDO DALAM MENDULANG SUARA PADA PEMILIHAN LEGISLATIF TAHUN 2019 (Studi Pada DPD Perindo Kabupaten Merangin)"

\section{Pembahasan}

\section{Strategi politik DPD Partai Perindo Kabupaten Merangin dalam mendulang} suara pada pemilihan legislatif tahun 2019

Pemilihan Umum (Pemilu) 2019 semakin dekat. Tahapannya pun telah dimulai. Sejumlah partai politik (parpol) baru akan menjalani debut pada kontestasi politik lima tahunan itu. Partai Persatuan Indonesia (Perindo) misalnya, yang menyatakan kesiapannya menghadapi persaingan politik dengan parpol lain yang lebih senior. Perindo yang baru berusia tiga tahun bahkan tak gentar mengungkapkan strategi pemenangan mereka. Bila tak ada aral melintang, hajatan Pemilu Legislatif akan digelar pada 17 April 2019, tahun depan. Sebanyak 20 partai peserta Pemilu yang terdiri dari 16 partai nasional dan 4 partai lokal (Aceh) akan bertarung memperebutkan kursi legislatif di tingkat kabupaten/kota, provinsi, dan pusat (nasional). 16 Partai nasional dimaksud yaitu: (1) PKB; (2) Gerindra; (3) PDIP; (4) Golkar; (5) NasDem; (6) Partai Garuda; (7) Partai Berkarya; (8) PKS; (9) Perindo (10) PPP (11) PSI (12) PAN (13) Hanura (14) Partai Demokrat; (19) Partai Bulan Bintang (PBB); (20) Partai Keadilan dan Persatuan Indonesia (PKPI).

Sementara 3 partai lokal Aceh (dan nomor urutnya) yang akan bertarung yaitu (15) Partai Aceh (16) Partai Sira (Aceh) (17) Partai Daerah Aceh; dan (18) Partai Nanggroe Aceh.

Dalam kontestasi Pemilu, tidak ada satu pun partai yang ingin kalah. Semuanya bermaksud meraih kemenangan. Untuk bisa menang dalam pertarungan, partai mutlak membutuhkan strategi pemenangan yang tepat. Pada titik inilah, ada kesamaan antara kontestasi Pemilu dan perang dalam militer. Perang membutuhkan strategi. Tidak ada kemenangan yang lahir tanpa strategi. Menang dan kalahnya sebuah peperangan sangat bergantung pada tepat atau tidaknya strategi yang digunakan. Begitu pun kontestasi Pemilu.

Secara etimologis, strategi berasal dari kata Yunani strategia, yang diartikan art and science of directing military forces, seni atau ilmu tentang mengatur dan mengarahkan kekuatan militer. Dengan kata lain, strategia atau strategos berarti seni menjadi seorang jenderal atau panglima perang. Dalam konteks di atas, strategi dimaknai sebagai cara untuk mendapatkan kemenangan atau mencapai tujuan. Jadi, partai yang ingin menang membutuhkan strategi untuk mencapainya. Di dalam strategi, tercakup taktik dan logistik.

Pada dasarnya, strategi dalam memenangi kontestasi Pemilu memiliki kemiripan dengan strategi perang. Tentu, ada pula yang membedakannya. Pembeda yang sangat kentara terletak pada target yang disasar untuk mencapai kemenangan. Dalam perang, target yang disasar adalah melemahkan dan merusak atau menghancurkan pasukan musuh baik fisik maupun moral (baca: mental), dan segala logistik perang serta hal pendukung lainnya sehingga pasukan musuh 
menyerah atau binasa. Dengan itu, kemenangan diraih. Sementara dalam kontestasi Pemilu, target yang disasar partai adalah simpati pemilih agar ia menjatuhkan pilihannya dalam Pemilu pada partai bersangkutan. Partai yang paling banyak dipilih oleh pemilih akan keluar sebagai pemenang. Jadi, pasukan menang dalam perang kalau musuh menyerah, sementara partai memenangi kontestasi pemilu kalau mendapatkan suara pemilih terbanyak.

Untuk pendatang baru, Partai Perindo adalah partai sangat massif menggunakan strategi pencitraan lewat media. Iklan kampanye muncul setiap hari di seluruh stasiun TV yang tergabung dalam MNC Group. iklan kampanye Partai Perindo tercatat sangat massif.

Berdasarkan wawancara dengan Bapak Selamet Edi Sucipto selaku Ketua DPD Perindo Kab. Merangin diketahui bahwa strategi yang dilakukan Partai Perindo dalam mendulang suara di parlemen pada pemilihan legislatif tahun 2019 diantaranya adalah:

\section{Sosialisasi}

Strategi pencitraan dan sosialisasi politik masih menjadi primadona, terutama melalui media TV. Saluran media sosial atau media baru juga semakin intens digunakan. Partai Perindo terlihat semakin agresif memanfaatkan dunia maya untuk kepentingan pencitraan dan sosialisasi politiknya.

Sebagai partai politik yang baru dan belum menjadi peserta pemilu sehingga belum memiliki representasi di legislatif, tentu saja Perindo belum bisa melaksanakan semua fungsi partai politik yang diutarakan di atas. Namun harus diakui bahwa Perindo sudah melakukan edukasi politik dan sosialisasi dengan gencar, misalnya melalui publikasi platform politik (Mengenal Platform Partai Perindo), mempopulerkan Mars Perindo, dan reportase kegiatan Ketua Umumnya saat melantik pengurus tingkat desa atau kelurahan di berbagai media massa eletronik dan cetak milik MNC Group, website, media sosial (Langkah HT fanpage), dan juga mewarnai forum-forum diskusi online. Melalui upaya gencar ini juga, Hary Tanoesoedibjo sebagai Ketua Umum Perindo secara simultan berhasil melaksanakan fungsi komunikasi politik dan merangsang opini publik.

Semua hal yang disosialisasikan tersebut nanti akan menjadi realita jika partai tersebut diberi kesempatan untuk bisa menang dalam pemilu. Strategi kampanye harus mampu dalam menjaring suara sebanyakbanyaknya baik dengan cara kampanye terbuka di lapangan, tertutup di gedung pertemuan, maupun rumah fungsionaris partai, juga melalui media online (blogger, whatApp facebook, twitter, youtube dst) dan perangkat telekomunikasi dan multimedia yang secara langsung berhubungan dengan konstituen secara interaktif. Segala jaminan atau janji partai untuk merealisasikan segala program yang dijanjikan tanpa disadari atau tidak mengandung nilai-nilai persuasif. Sehingga ada sebagian dari masyarakat yang menerima informasi tersebut terdorong hatinya untuk memberi kepercayaan dan memilih partai ini dalam pemilu.

2. Penempatan Caleg Potensial Per Dapil

Berdasarkan data yang diperoleh pada Kantor DPD Perindo Kabupaten Merangin diketahui bahwa Partai Perindo mengusung 34 Caleg yang akan bertarung di 4 Dapil, dimana Dapil 1 dan 2 merupakan caleg terbanyak yang ditempatkan Perindo yakni 11 Caleg, sementara Dapil 3 berjumlah 7 Caleg dan Dapil 4 sebanyak 5 Caleg, dengan rincian sebagai berikut:

a. Dapil 1

Terdiri dari Kecamatan Bangko, Bangko Barat, Renah Pemberap, Sungai Manau, Pangkalan Jambu, Nalo Tantan, dan Batang Masumai, dengan caleg yang diusung: 
1) Slamet Edi Sucipto, S.Pd, SE, ME

2) Zulkifli

3) Elissetiana, S.Pd

4) Hasan Zuhdi

5) Samsul Hijar

6) Laila Susanti, Amd

7) Umi Salamah, Am.Keb

8) Suryono

9) Asy Syahrul, SE

10) Bakar

b. Dapil 2

11) Bety Heryanti

Terdiri dari Kecamatan Tabir, Tabir Lintas, Margo Tabir, Tabir Ilir, Tabir Selatan, Tabir Timur, Tabil Ulu, dan Tabir Barat, dengan caleg yang diusungkan:

1) Muhammad Zen

2) Rabai

3) Siti Dianti, SE

4) Em Fajri

5) Bustami

6) Desi Susanti, S.Pd

7) Hayatuloh, Amd

8) Rudi Hartono

9) Kasriyanti

10) Anggun Dia. A

11) Sukadi

c. Dapil 3

Terdiri dari Kecamatan Pamenang, Pamenang Selatan, Pamenang Barat, dan Renah Pamenang, dengan caleg yang diusung yaitu:

1) Slamet Sriyanto

2) Munjiyah, S.Pd. Aud

3) Andi Husni, SE

4) Muhammad Simi, SE

5) Bambang Indra

6) Wely Kisma

7) Nuraini, SP

d. Dapil 4

Terdiri dari Kecamatan Tiang Pumpung, Muara Siau, Lembah Masurai, Jangkat, dan Jangkat Timur, dengan caleg yang diusung yaitu:

1) Hasren Purja Sakti

2) Guntur Amir Putra

3) Pepy Yusmayur Helpi, S.Pd

4) Zainuddin

5) Evi Herlina

3. Program UMKM dan Pro Rakyat

Salah satu strategi pemenangan yang dilakukan oleh Partai Perindo Pusat hingga daerah adalah Pembagian gerobak bagu UMKM, dimana Partai Perindo terus berlangsung di berbagai pelosok daerah. Telah banyak pedagang yang mendapatkan manfaat karena omzetnya meningkat setelah mendapat gerobak baru tanpa dipungut biaya sepeser pun. Hal ini sebagaimana diungkapkan Bapak Feri Yanto selaku Pengurus DPD Perindo Kab. Merangin

Program gerobak UMKM diinisiasi Partai Perindo dalam tiga tahun terakhir ini telah berhasil mensejahterakan pelaku UMKM dan pedagang kecil. Sumbangsih gerobak Perindo dalam meningkatnya pertumbuhan ekonomi dirasakan betul 
masyarakat luas. Hal ini sebagaimana diungkapkan Bapak Selamet Edi Sucipto selaku Ketua DPD Perindo Kab. Merangin:

Kendala DPD Partai Perindo Kabupaten Merangin dalam menerapkan strategi politik DPD Partai Perindo Kabupaten Merangin untuk mendulang suara pada pemilihan legislatif tahun 2019

1. Rendahnya Partisipasi Politik Masyarakat

Berdasarkan pengalaman pada beberapa pemilihan terdahulu banyak masyarakat yang dalam kenyataannya memiliki pastisipsi yang rendah terhadap politik. Contohnya pada saat terjadi pemilihan umum disuatu daerah yang daftar pemilih tetapnya 350 tapi yang datang ke TPS dan menggunakan hak pilihnya hanya 200 rang saja, itu artinya hampir 50\% masyarakat tidak menggunakan hak pilihnya. Masyarakat tidak peduli siapa pun yang akan terpilih menjadi pemimpin mereka, padahal itu akan menjadi pemimpin yang akan membimbing mereka untuk menjadi masyarakat yang lebih maju lagi seperti yang dicita-citakan masyarakat.

2. Adanya Money Politik dalam Pileg

3. Struktur Pengurusan Partai Perindo yang Belum Kuat

\section{Penutup}

Kesimpulan dari penelitian ini adalah 1)Strategi politik DPD Partai Perindo Kabupaten Merangin dalam memenangkan Pemilu 2019 diantaranya adalah melakukan sosialisasi program dan pencitraan partai serta melakukan pemetaan dapil potensial dengan menempatkan tokoh masyarakat sebagai caleg. 2) kendala DPD Partai Perindo Kabupaten Merangin dalam menerapkan strategi politik untuk memenangkan Pemilu 2019 diantaranya adalah rendahnya partisipasi politik masyarakat dan adanya politik uang yang dilakukan caleg partai lain, serta belum kuatnya struktur di tingkat bawah.

Diharapkan Partai Perindo memberikan pendidikan politik kepada masyarakat melalui kadernya yang terdaftar di caleg berdasarkan dapil masing-masing melalui edukasi politik sehat, agar partai Perindo tidak hanya memenangkan Pemilu 2019

\section{Referensi} namun juga memenangkan hati masyarakat.

Arifin, Anwar. (2003). Ilmu Komunikasi : Suatu Pengantar Ringkas. Raja Grafindo Persada.

Armenia, R. (2016). Perindo Jadi Partai Paling Aktif Kampanye di Media Sosial. CNN Indonesia. https://www.cnnindonesia.com/nasional/20160330194759-32-120647/perindo-jadipartai-paling-aktif-kampanye-di-media-sosial

Budiardjo, M. (2009). Dasar- dasar Ilmu Politik. PT. Gramedia Pustaka Utama.

Cangara, Hafied. (2011). Komunikasi Politik Konsep, Teori, dan Strategi. PT. Raja Grafindo Persada, Efriza. (2012). Political Explore: Sebuah Kajian Ilmu Politik. Alfabeta

Imawan. (1997). Membedah politik Orde Baru. Pustaka. Pelajar.

Kurniawan, H. (2015). HT Masuk 5 Besar Presiden Pilihan Rakyat. Sindonews.

https://nasional.sindonews.com/read/1055114/12/ht-masuk-5-besar-presiden-pilihanrakyat-1445429904

Nasution, Arif. (2000). Demokrasi dan Problema Otonomi Daerah. Mandar Maju.

Nimmo, Dan. (2004). Komunikasi Politik, Komunikator, Pesan, dan Media. PT. Remaja Rosdakarya.

Pasaribu, P. (2017). Peranan Partai Politik dalam Melaksanakan Pendidikan Politik. JPPUMA Jurnal Ilmu Pemerintahan Dan Sosial Politik Universitas Medan Area, 5(1), 51-59.

Prasetya, I. Y. (2011). Pergeseran peran ideologi dalam partai politik. Jurnal Ilmu Politik Dan Ilmu Pemerintahan, 1(1), 30-40.

Rahman H.I, Abdulkadir.( 2007). Sistem Politik Indonesia. Graha Ilmu.

Sukarna. (2002). Perbandingan Sistem Politik. PT. Citra Aditya Bakti.

Salusu, J. (2006). Pengambilan Keputusan Strategik Untuk Organisasi Publik dan Organisasi Non Profit. Grasindo.

Undang-Undang Republik Indonesia Nomor 7 Tahun 2017 Tentang Pemilihan Umum 